\title{
Weight management as a cardioprotective intervention raises issues for nutritional scientists regarding clinical ethics
}

\author{
Lucy Aphramor \\ Coventry University, Coventry, $U K$
}

Weight management through lifestyle change is an accepted recommendation in the primary prevention and secondary treatment of CHD in UK policy (British Association for Cardiac Rehabilitation (BACR) guidelines ${ }^{(1)}$ ) and underpins European-wide programmes ${ }^{(2)}$. However, it is also recognised that weight management remains an elusive goal for most patients ${ }^{(3)}$ and that lifestyle change can improve metabolic risk independent of weight loss ${ }^{(4)}$. Thus, cardioprotective dietary treatment decisions raise ethical issues for nutritional scientists that have not been widely debated ${ }^{(5)}$.

The study relied on two methodologies. First, it used standard techniques from evidence-based medicine ${ }^{(6)}$ to assess the appropriateness of papers cited in support of weight-loss recommendations in UK and European-wide CHD management programmes. Two examples are

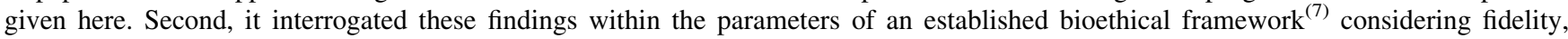
veracity, justice, a caring response, beneficence and nonmaleficence. It considered claims for the clinical effectiveness of weight man-

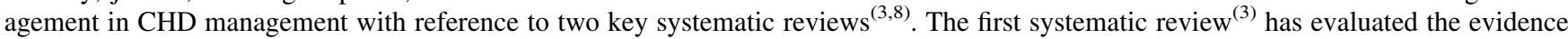
for the effectiveness of energy restriction in achieving sustained weight loss. The authors conclude that rather than supporting energy restriction for (cardiac) health, evidence to date implicates dieting in adverse health outcomes, including concern about weight cycling on all-cause and cardiac mortality. The second review ${ }^{(8)}$ is a systematic review of evidence on dietary advice to prevent further events in individuals with existing CVD. No evidence was found to support a recommendation of weight loss.

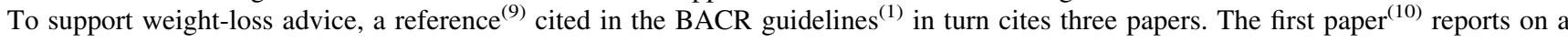
number of studies investigating weight change in relation to cardiovascular risk factors. It is not a systematic review of the evidence nor does it contain any systematic reviews. The parameters of the trials included (e.g. $n 9 ; 10$ weeks duration) render it unsuitable to support the claims made for it $^{(6)}$; the original authors qualify their statements throughout: 'the possible effects of exercise were difficult to determine'; 'it cannot be proven that weight loss per se is the most important trigger of the reduced mortality'; 'data on the effects of weight loss on $\mathrm{Lp}(\mathrm{a})$ are scarce and contradictory. Further studies are needed. ${ }^{(10)}$. Claims for benefits of weight loss are inadequately referenced throughout the European guidelines ${ }^{(6)}$. For example, the statement 'Intentional weight loss in obese patients can improve or prevent many of the obesity-related risk factors for CHD' is not supported by a citation. Further, it is contradicted by the evidence ${ }^{(3,8)}$. Other studies used by European programmes to support weight-loss claims are inappropriate: one even has no methodology ${ }^{(11)}$. Hence, references cited in the literature to support weight-loss recommendations in patients with a BMI $>25 \mathrm{~kg} / \mathrm{m}^{2}$ are not fit for purpose. Clearly, this misrepresentation of data in CHD guidelines is methodologically problematic.

There are also ethical implications related to maleficence and nonmaleficence. This finding has implications for nutritional scientists in terms of professional duty, accountability, informed consent, clinical effectiveness and research directions.

1. Coats A, McGee H, Stokes H \& Thompson D (2007) BACR Guidelines for Cardiac Rehabilitation. Oxford: Blackwell Science Ltd.

2. Graham I, Atar B, Borch-Johnsen K et al. (2007) Eur Heart J 14, Suppl. 2, E1-E40.

3. Mann T, Tomiyama AJ, Westling E, Lew AM, Samuels B \& Chatman J (2007) Am Psychol 62, 220-233.

4. Bacon L, Stern JS, Van Loan MD \& Keim NL (2005) J Am Diet Assoc 105, 929-936.

5. Aphramor L (2005) Soc Theory Health 3, 315-340.

6. Public Health Resource Unit (2008) Appraisal tools. http://www.phru.nhs.uk/Pages/PHD/resources.htm

7. Beauchamp T \& Childress F (2001) Principles of Biomedical Ethics, 5th ed. Oxford: Oxford University Press.

8. Mead A, Atkinson G, Albin D et al. (2006) J Hum Nutr Diet 19, 401-419.

9. Reddy S (2006) Care pathway for the management of overweight and obesity. Part of the Your weight, your health series. http://www.dh.gov.uk/en/ Publicationsandstatistics/Publications/PublicationsPolicyAndGuidance/DH_4134408

10. Van Gaal LF, Wauters MA \& De Leeuw IH (1997) Int J Obes Relat Metab Disord 21, Suppl. 1, S5-S9.

11. Anderson W'\& Konz E (2001) Obes Res 9, Suppl. 4, 326S-334S. 